\title{
Associations between TV viewing, sitting time, physical activity and insomnia among 100,839 Brazilian adolescents
}

\author{
André O. Werneck ${ }^{\mathrm{a}, *}$, Davy Vancampfort ${ }^{\mathrm{b}}$, Adewale L. Oyeyemi ${ }^{\mathrm{c}}$, Brendon Stubbs ${ }^{\mathrm{d}, \mathrm{e}}$, \\ Danilo R. Silva ${ }^{\mathrm{f}}$ \\ a Study and Research Group in Metabolism, Nutrition, and Exercise (GEPEMENE), State University of Londrina, Rodovia Celso Garcia Cid, km 380, 86057-970 Londrina, \\ Parana, Brazil \\ ${ }^{\mathrm{b}}$ Department of Rehabilitation Sciences, KU Leuven - University of Leuven, Leuven, Belgium \\ ${ }^{\mathrm{c}}$ Department of Physiotherapy, College of Medical Sciences, University of Maiduguri, Maiduguri, Borno State, Nigeria \\ d Department of Psychological Medicine, Institute of Psychiatry, Psychology and Neuroscience, King's College London, De Crespigny Park, London SE5 8AF, UK \\ e South London and Maudsley NHS Foundation Trust, London, UK \\ ${ }^{\mathrm{f}}$ Departament of Physical Education, Federal University of Sergipe - UFS, São Cristóvão, Brazil
}

\section{A R T I C L E I N F O}

\section{Keywords:}

Physical activity

Sedentary lifestyle

Mental health

Depression

Youth

\begin{abstract}
A B S T R A C T
Our aim was to examine the relationship between insomnia and levels of physical activity (PA) and time spent sitting and TV viewing among Brazilian adolescents. Data from the Brazilian Scholar Health Survey, a nationally representative survey of 9th grade adolescents [mean: 14.28 years (range: 11-18 years)] conducted in 2015 ( $n=100,839$ ) were used. Self-reported insomnia, TV viewing, sitting time and total PA (adapted International PA Questionnaire) were collected. Chronological age, race, type of city (capital or interior) country region, goodies ingestion and ultra-processed foods ingestion were covariates. Logistic regression analyses were conducted to assess the associations. A higher sitting time and TV viewing ( $\geq 8 \mathrm{~h}$ /day) was associated with a higher risk of insomnia among boys [sitting time: OR $=2.39 \quad(95 \% \mathrm{CI}=1.88-3.04)$; $\mathrm{TV}: \mathrm{OR}=2.49(95 \% \mathrm{CI}=1.92-3.22) \quad$ and $\quad$ girls $\quad[$ sitting $\quad$ time: $\quad \mathrm{OR}=2.17(95 \% \mathrm{CI}=1.84-2.57$; $\mathrm{TV}: \mathrm{OR}=1.72(95 \% \mathrm{CI}=1.44-2.04)]$. More than $4 \mathrm{~h}$ of sitting time per day was associated with higher risk of insomnia in adolescents who comply [boys: $\mathrm{OR}=1.43(95 \% \mathrm{CI}=1.19-1.73)$; girls: $\mathrm{OR}=1.66(95 \% \mathrm{CI}=1.41-1.94)]$ and who do not comply with the $300 \mathrm{~min} /$ week of physical activity recommendation $[$ boys $=\mathrm{OR}=1.35(95 \% \mathrm{CI}=1.13-1.60)$; girls: $\mathrm{OR}=1.38(95 \% \mathrm{CI}=1.20-1.57)$ ]. Our data suggest that higher levels of TV viewing or sitting are associated with sleep difficulties in this large cohort of adolescents, irrespective of their physical activity behavior.
\end{abstract}

\section{Introduction}

Insufficient sleep and sleepiness are serious public health concern in adolescents (Owens, 2014). Insomnia disorder is the most severe clinical manifestation of recurrent and chronic perceived sleep dissatisfaction (i.e. difficultly falling asleep and staying asleep despite having an adequate opportunity to sleep) (American Psychiatric Association, 2013). It occurs several times per week during several months and results in significant daytime distress, difficulties with attention, concentration and memory, and mood lability. The prevalence of insomnia in adolescence ranges between 4\% and 39\% depending on the diagnostic criteria used (De Zambotti et al., 2017). Insomnia is frequently comorbid with other mental conditions, with half of adolescents with insomnia also reporting comorbid psychiatric disorders
(Johnson et al., 2006). Through direct and indirect relationships (via substance use, mood and anxiety disorders) insomnia is furthermore associated with suicidal behavior (Wong et al., 2016). Next to potential severe psychiatric consequences, lack of sleep among adolescents is also associated with higher cardio-metabolic risks (Countryman et al., 2013). Adolescent girls are at a higher risk after the onset of menarche, suggesting that hormonal changes underlying puberty may be directly or indirectly involved (Johnson et al., 2006). Previously reported potentially modifiable risk factors of insomnia among adolescents include electronic media use (Lange et al., 2017), school stress (Roberts et al., 2008), and the consumption of highly caffeinated beverages (Koivusilta et al., 2016; Owens et al., 2014).

There are two main approaches for the treatment of insomnia in adolescence, i.e. cognitive behavioral therapy and pharmacotherapy.

\footnotetext{
* Corresponding author.

E-mail address: andreowerneck@gmail.com (A.O. Werneck).
} 
Table 1

Characteristics of the sample according to sex.

\begin{tabular}{|c|c|c|c|c|}
\hline & $\mathrm{N}$ & Male \% (IC 95\%) & $n$ & Female \% (IC 95\%) \\
\hline \multicolumn{5}{|l|}{ Age } \\
\hline$<14$ years & 7084 & $16.1(15.4-16.7)$ & 10019 & $20.4(19.8-21.1)$ \\
\hline 14 years & 23,428 & $48.8(48.0-49.6)$ & 27,651 & $53.3(52.5-54.0)$ \\
\hline$>14$ years & 18,047 & $35.1(34.4-35.8)$ & 14610 & $26.3(25.7-26.9)$ \\
\hline \multicolumn{5}{|c|}{ Country region } \\
\hline North & 11,531 & $9.5(9.3-9.8)$ & 12,080 & $9.6(9.3-9.9)$ \\
\hline Northeast & 16,727 & $26.3(25.8-26.9)$ & 19,196 & $29.0(28.5-29.6)$ \\
\hline Southeast & 8601 & $44.4(43.6-45.3)$ & 8982 & $42.4(41.6-43.2)$ \\
\hline South & 4804 & $12.1(11.7-12.5)$ & 4935 & $11.6(11.2-12.1)$ \\
\hline Midwest & 6896 & $7.6(7.4-7.8)$ & 7087 & $7.3(7.1-7.5)$ \\
\hline \multicolumn{5}{|l|}{ Type of city } \\
\hline Capital & 24,511 & $23.2(22.7-23.7)$ & 26,098 & $22.8(22.3-23.3)$ \\
\hline Non-capital & 24,048 & $76.8(76.2-77.3)$ & 26,182 & 77.2 (76.7-77.7) \\
\hline \multicolumn{5}{|l|}{ Skin color } \\
\hline White & 18,635 & $41.1(40.3-41.9)$ & 19,340 & $39.6(38.9-40.0)$ \\
\hline Other & 29,924 & 58.9 (58.1-59.7) & 32,940 & $60.4(59.6-61.1)$ \\
\hline \multicolumn{5}{|c|}{ Goodies consumption } \\
\hline 0 times & 6764 & $13.1(12.6-13.7)$ & 4733 & $8.3(7.9-8.7)$ \\
\hline $1-3$ times & 20,537 & $41.1(40.4-42.0)$ & 18,879 & $35.1(34.4-35.8)$ \\
\hline$\geq 4$ times & 21,116 & $45.7(44.9-46.5)$ & 28,568 & $56.6(55.9-57.4)$ \\
\hline \multicolumn{5}{|c|}{ Ultra-processed foods consumption } \\
\hline 0 times & 8008 & $15.7(15.2-16.3)$ & 7831 & $13.9(13.4-14.4)$ \\
\hline $1-3$ times & 20,965 & $44.2(43.4-45.0)$ & 21,808 & $42.4(41.7-43.2)$ \\
\hline$\geq 4$ times & 19,444 & $40.1(39.3-40.9)$ & 22,541 & $43.6(42.9-44.4)$ \\
\hline \multicolumn{5}{|c|}{ Insomnia due to concerns } \\
\hline No & 45,121 & 93.1 (92.7-93.5) & 44,095 & $84.5(84.0-85.1)$ \\
\hline Yes & 3438 & $6.9(6.5-7.3)$ & 8185 & $15.5(14.9-16.0)$ \\
\hline \multicolumn{5}{|l|}{ Total PA } \\
\hline $0 \mathrm{~min}$ & 1610 & $2.8(2.6-3.1)$ & 3879 & $6.6(6.2-7.0)$ \\
\hline $1-59 \mathrm{~min}$ & 4756 & $9.8(9.3-10.3)$ & 9173 & $17.3(16.7-17.9)$ \\
\hline $60-119 \min$ & 5693 & $11.7(11.2-12.3)$ & 8498 & $16.8(16.2-17.4)$ \\
\hline $120-179 \mathrm{~min}$ & 5857 & $12.5(12.0-13.10$ & 7539 & $14.8(14.3-15.4)$ \\
\hline $180-239 \mathrm{~min}$ & 5046 & $10.3(9.8-10.7)$ & 5456 & $10.8(10.3-11.3)$ \\
\hline $240-299 \mathrm{~min}$ & 4576 & $9.6(9.1-10.1)$ & 4571 & $8.9(8.5-9.4)$ \\
\hline $300-359 \mathrm{~min}$ & 3928 & $8.0(7.5-8.4)$ & 3462 & $6.3(5.9-6.6)$ \\
\hline $360-419 \mathrm{~min}$ & 3458 & $7.4(7.0-7.8)$ & 2657 & $5.3(4.9-5.6)$ \\
\hline$\geq 420 \mathrm{~min}$ & 13,635 & $27.9(27.2-28.6)$ & 7045 & $13.2(12.7-13.8)$ \\
\hline \multicolumn{5}{|l|}{ TV view } \\
\hline$<1 \mathrm{~h}$ & 13,005 & $25.8(25.1-26.5)$ & 13,629 & $24.5(23.8-25.1)$ \\
\hline $1-1.99 \mathrm{~h}$ & 7806 & $16.0(15.4-16.6)$ & 7691 & $14.1(13.6-14.6)$ \\
\hline $2-2.99 \mathrm{~h}$ & 7000 & $13.6(13.0-14.1)$ & 6697 & $13.0(12.4-13.5)$ \\
\hline $3-3.99 \mathrm{~h}$ & 5874 & $12.8(12.2-13.3)$ & 6066 & $11.6(11.1-12.1)$ \\
\hline $4-4.99 \mathrm{~h}$ & 4174 & $8.8(8.4-9.3)$ & 4543 & $8.8(8.4-9.3)$ \\
\hline $5-5.99 \mathrm{~h}$ & 3076 & $6.7(6.3-7.1)$ & 3578 & $7.4(7.0-7.8)$ \\
\hline $6-6.99 \mathrm{~h}$ & 1738 & $3.6(3.3-3.9)$ & 2130 & $4.2(3.9-4.5)$ \\
\hline $7-7.99 \mathrm{~h}$ & 1404 & $3.0(2.7-3.3)$ & 2080 & $4.3(4.0-4.6)$ \\
\hline$\geq 8 \mathrm{~h}$ & 4482 & $9.8(9.3-10.3)$ & 5866 & $12.3(11.8-12.8)$ \\
\hline \multicolumn{5}{|l|}{ Sitting time } \\
\hline$<1 \mathrm{~h}$ & 9854 & $20.0(19.4-20.6)$ & 10,335 & 18.7 (18.2-19.3) \\
\hline $1-1.99 \mathrm{~h}$ & 6249 & $12.6(12.1-13.2)$ & 6539 & $12.2(11.7-12.7)$ \\
\hline $2-2.99 \mathrm{~h}$ & 6333 & $12.8(12.3-13.4)$ & 6138 & $11.4(10.9-11.9)$ \\
\hline $3-3.99 \mathrm{~h}$ & 6113 & $12.1(11.6-12.7)$ & 6096 & $11.7(11.2-12.2)$ \\
\hline $4-4.99 \mathrm{~h}$ & 5211 & $10.7(10.2-11.2)$ & 5193 & $9.6(9.1-10.0)$ \\
\hline $5-5.99 \mathrm{~h}$ & 4165 & $9.2(8.7-9.6)$ & 4469 & $9.0(8.5-9.5)$ \\
\hline $6-6.99 \mathrm{~h}$ & 2749 & $5.8(5.5-6.2)$ & 3176 & $6.5(6.1-7.0)$ \\
\hline $7-7.99 \mathrm{~h}$ & 1926 & $3.9(3.6-4.3)$ & 2710 & $5.4(5.1-5.8)$ \\
\hline$\geq 8 \mathrm{~h}$ & 5959 & $12.8(12.2-13.3)$ & 7624 & $15.4(14.8-16.0)$ \\
\hline
\end{tabular}

Note. CI, confidence interval; PA, physical activity; TV, television.

Both approaches can be used in isolation or combination. Cognitive behavioral techniques include arousal reduction (quieting pre-bedtime activities and relaxation-imagery), improving sleep hygiene practices (increase behaviors and environmental conditions that promote improved sleep quality), stimulus control (adopt regular schedules, consolidate sleep to night-time, and improve bed-sleep association), and sleep restriction (temporarily limit hours in bed to increase sleep efficiency) (Zhou and Owens, 2016). Most used medication to treat insomnia are benzodiazepines, melatonin, pyrimidine derivatives (e.g., zolpidem), a-receptor agonists (e.g., clonidine), sedating antihistamines (e.g., hydroxyzine) and sedating antidepressants (e.g., trazodone) (Owens et al., 2005). Pharmacotherapy might however have side- effects while a common problem with cognitive behavioral therapy among adolescents is compliance with the protocol (Bootzin and Stevens, 2005).

Given the prevalence and burden of insomnia in adolescence, it is essential to understand all modifiable risk factors so that comprehensive and targeted interventions can be designed for this population. Next to limiting electronic media use, coping with school stress, and limiting the consumption of highly caffeinated beverages, promoting physical activity and limiting sedentary behavior might be promising. For example, research shows that 30 minutes of running in the morning during weekdays for three consecutive weeks impacted positively on sleep and psychological functioning in healthy adolescents compared 

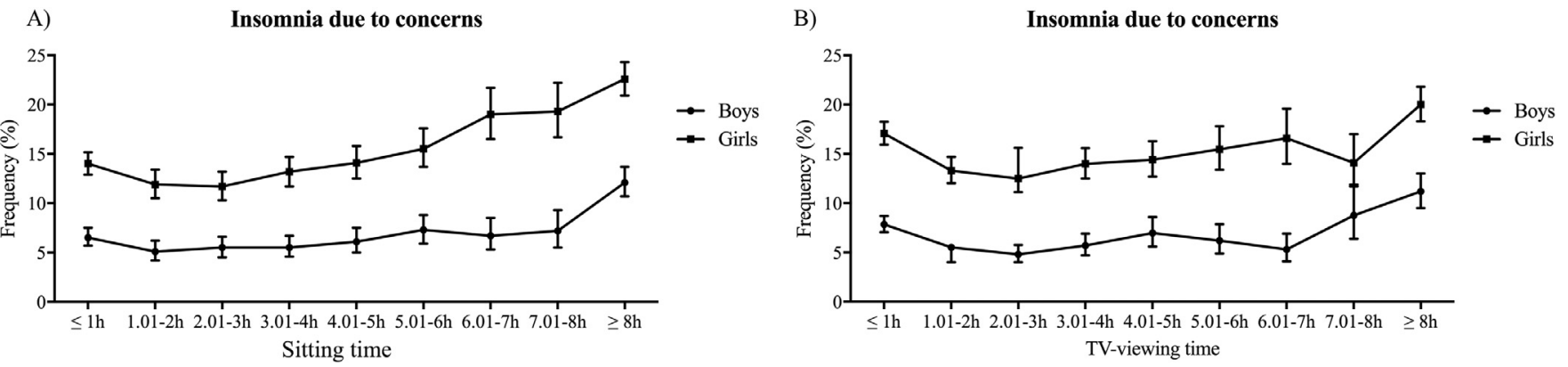

Fig. 1. Prevalence of insomnia according to sitting time (A) and TV viewing (B) patterns.

Note. TV, television.

Table 2

Association between sitting time, TV viewing, physical activity and insomnia due to concerns.

\begin{tabular}{|c|c|c|}
\hline & \multicolumn{2}{|l|}{ Sex } \\
\hline & Boys OR (CI 95\%) & Girls OR (CI 95\%) \\
\hline \multicolumn{3}{|c|}{ Sitting time (per day) } \\
\hline$<1 \mathrm{~h}$ & $1.19(0.93-1.52)$ & $1.19(1.01-1.41)$ \\
\hline $1-1.99 \mathrm{~h}$ & $0.93(0.70-1.24)$ & $1.00(0.82-1.22)$ \\
\hline $2-2.99 \mathrm{~h}$ & 1 & 1 \\
\hline $3-3.9 \mathrm{~h}$ & $1.02(0.77-1.34)$ & $1.14(0.95-1.38)$ \\
\hline $4-4.99 \mathrm{~h}$ & $1.12(0.84-1.50)$ & $1.24(1.02-1.50)$ \\
\hline $5-5.99 \mathrm{~h}$ & $1.36(1.02-1.81)$ & $1.39(1.14-1.70)$ \\
\hline $6-6.99 \mathrm{~h}$ & $1.23(0.89-1.69)$ & $1.78(1.43-2.22)$ \\
\hline $7-0.7 .99 \mathrm{~h}$ & $1.33(0.95-1.86)$ & $1.79(1.43-2.24)$ \\
\hline$\geq 8 \mathrm{~h}$ & $2.39(1.88-3.04)$ & $2.17(1.84-2.57)$ \\
\hline \multicolumn{3}{|c|}{ TV viewing (per day) } \\
\hline$<1 \mathrm{~h}$ & $1.66(1.33-2.08)$ & $1.42(1.22-1.66)$ \\
\hline $1-1.99 \mathrm{~h}$ & $1.16(0.90-1.50)$ & $1.07(0.90-1.27)$ \\
\hline $2-2.99 \mathrm{~h}$ & 1 & 1 \\
\hline $3-3.9 \mathrm{~h}$ & $1.20(0.91-1.59)$ & $1.13(0.94-1.36)$ \\
\hline $4-4.99 \mathrm{~h}$ & $1.48(1.10-2.00)$ & $1.17(0.96-1.42)$ \\
\hline $5-5.99 \mathrm{~h}$ & $1.30(0.95-1.78)$ & $1.27(1.02-1.57)$ \\
\hline $6-6.99 \mathrm{~h}$ & $1.11(0.79-1.56)$ & $1.37(1.07-1.74)$ \\
\hline 7-.799 h & $1.87(1.26-2.78)$ & $1.11(0.86-1.44)$ \\
\hline$\geq 8 \mathrm{~h}$ & $2.49(1.92-3.22)$ & $1.72(1.44-2.04)$ \\
\hline \multicolumn{3}{|c|}{ Physical activity (per week) } \\
\hline $0 \mathrm{~min}$ & 1 & 1 \\
\hline$<60 \min$ & $0.68(0.46-0.99)$ & $0.87(0.72-1.05)$ \\
\hline $60-119 \min$ & $0.67(0.47-0.96)$ & $0.79(0.65-0.95)$ \\
\hline $120-179 \mathrm{~min}$ & $0.53(0.36-0.76)$ & $0.86(0.71-1.04)$ \\
\hline $180-239 \mathrm{~min}$ & $0.51(0.35-0.74)$ & $0.85(0.69-1.04)$ \\
\hline $240-299 \mathrm{~min}$ & $0.55(0.37-0.80)$ & $0.88(0.71-1.10)$ \\
\hline 300-359 min & $0.60(0.41-0.88)$ & $0.93(0.76-1.15)$ \\
\hline $360-419 \mathrm{~min}$ & $0.57(0.39-0.83)$ & $0.88(0.69-1.12)$ \\
\hline$\geq 420 \mathrm{~min}$ & $0.72(0.52-0.99)$ & $1.06(0.88-1.27)$ \\
\hline
\end{tabular}

Note. Analysis adjusted for age group, race, country region, type of city (capital or interior), physical activity/sitting time, goodies ingestion and ultra-processed foods ingestion. OR, odds ratio. CI, confidence interval.

with a control group (Kalak et al., 2012). However, the relationship between physical activity, sedentary behavior and insomnia is complex and poorly understood. While on one hand, evidence shows that engaging in physical activity can alleviate or prevent sleep problems among adolescents (Lang et al., 2016), on the other hand, insomnia can lead to disengagement in physical activity and increased engagement in sedentary behaviors (Brunetti et al., 2016).

Despite some recent advancement in understanding the complex relationships, studies examining associations between physical activity, sedentary behavior and insomnia among adolescents in the low-andmiddle-income countries (LMICs) are scarce. In the only nation-wide study to date, screen time among adolescents from Iran was higher in those with insomnia (Mozafarian et al., 2017). Second, it remains to be explored in more detail how much time spent sitting and how much time spent watching TV are associated with insomnia and how much time spent physically active might be protective. Third, more research exploring context specific sedentary behavior such as TV viewing is needed, so as to provide important insights into the underlying relationships between sedentary behavior and insomnia. For example, previous research among adults in a high income setting demonstrated that mainly passive sedentary behavior (TV viewing) is related with adverse mental health outcomes, while more cognitive challenging sedentary behaviors such as reading, and computer and internet use are to a lesser extent associated with depressive symptoms (Hamer and Stamatakis, 2014). These data however still need to be confirmed in adolescents. Exploring associations between the presence of insomnia and sedentary behavior in LMICs is of particular importance given different socio-cultural structures, methods of transportation, and environmental factors (e.g., safety, climate) compared with high income countries (Arat and Wong, 2017).

The continuing dearth of studies from this part of the world also highlights the gap between where research is conducted and where the largest public health impacts of physical inactivity will occur (Sallis et al., 2016). However, given that sleep problems have been highlighted as a growing problem in LMICs (Koyanagi et al., 2018; Peltzer and Pengpid, 2017; Stranges et al., 2012) and that interaction between factors that result in insomnia tend to vary according to social and cultural conditions, information from nationally representative samples in LMICs is warranted. Therefore, the present study examined the relationship between insomnia and levels of physical activity, and time spent sitting and time spent TV viewing in a representative sample of Brazilian adolescents. A second aim was to investigate the interaction effect of being physically active and TV viewing on insomnia.

\section{Methods}

\subsection{Sample and procedure}

Data from the current study were derived from the Brazilian Scholar Health Survey (PeNSE in Portuguese). PeNSE was conducted in 2015 with the goal to investigate the risk/protective factors related to health in adolescents from public and private schools in Brazil (IBGE, 2016). The survey included a representative sample of students from the final (9th) year of elementary education, which was selected using a complex multi-stage, stratified, clustered probability design.

The sampling process and methods are detailed elsewhere (IBGE, 2016). Briefly, the cluster sampling was performed in two stages in capital cities (with schools as primary units and classes as secondary units) and three stages in other municipalities (with municipalities as primary units, schools as secondary units and classes as tertiary units). The proportion utilized for type of school (public or private) was based on the proportion of the total population enrolled in each type of school, which was also included in the estimation of sampling weights. From 3160 eligible schools, a sample of 3040 schools, with 124,227 students was eligible to be included in the survey. Of these students, only 102,301 accepted to participate or were at school on the days of 


\section{Insomnia due to concerns}

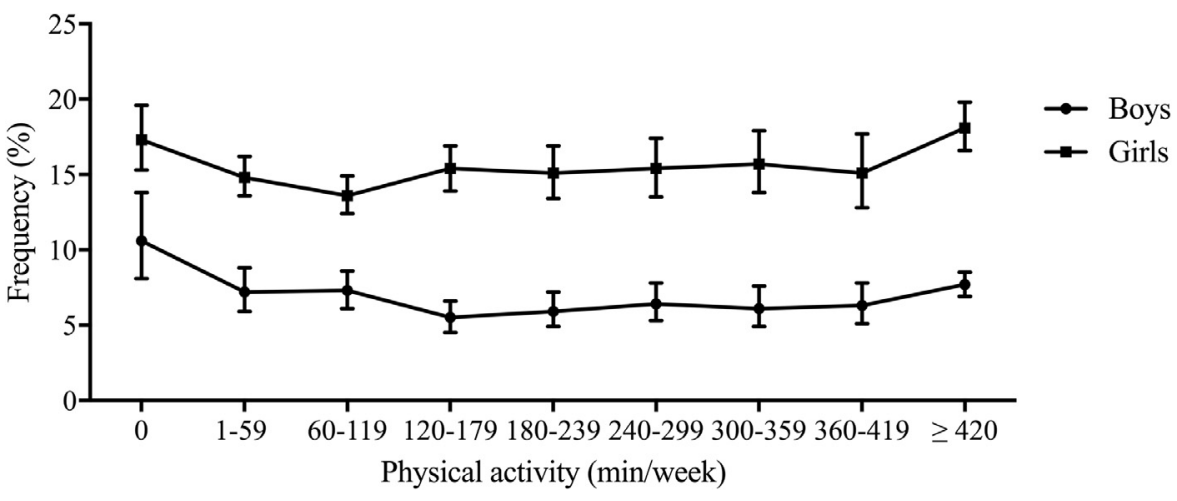

Fig. 2. Prevalence of insomnia according to physical activity patterns.

\section{Boys}

Insomnia due to concerns

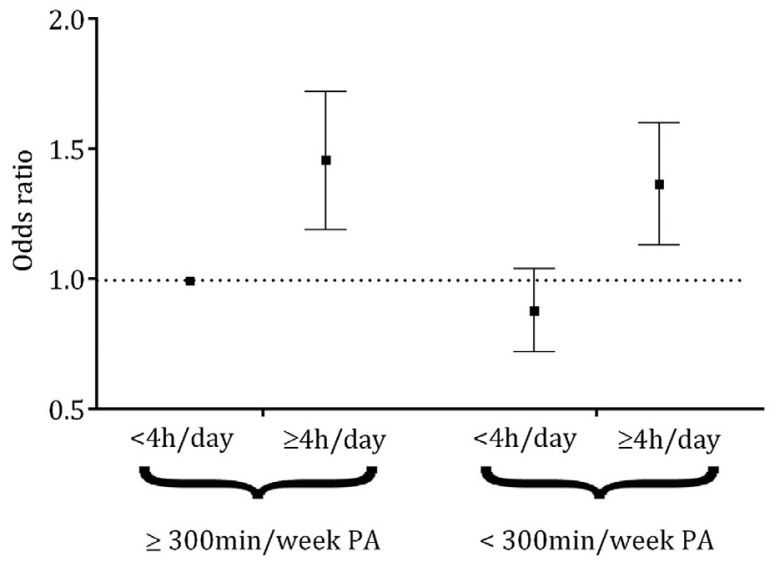

Girls

Insomnia due to concerns

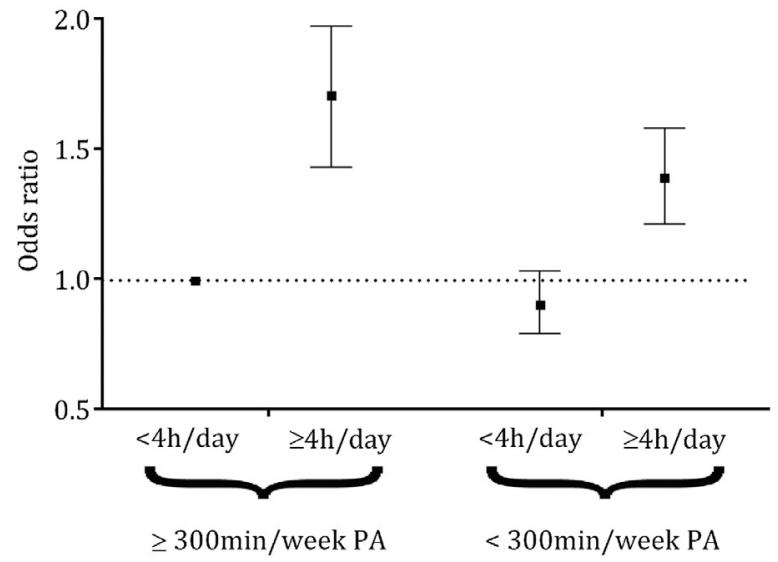

Fig. 3. Association between physical activity, sitting time and insomnia due to concerns.

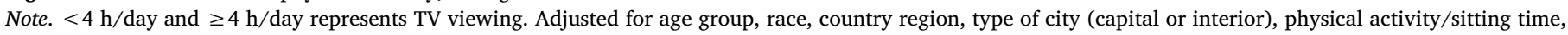
goodies ingestion and ultra-processed foods ingestion. OR, odds ratio. CI, confidence interval.

interview. Due to missing data, the current analyses considered data from 100,839 students for general analyses and 100,595 students for analyses including dietary patterns at 3040 schools.

Data were collected by self-administered questionnaires, which consisted of two sections. The first, which focused on the contextual characteristics of the school, was answered by the school director/coordinator with questions concerning the school and what the school offers (e.g. number of enrolled students; if the school offers sports after classes; structure of the school's sports and study facilities; what is on sale in the school canteen). The second section was self-administered by the students and covered individual characteristics and information on physical activity and sedentary behavior. All procedures were approved by the Research Ethics National Council of the National Health Council, and the study was conducted in accordance with the principles expressed in the Declaration of Helsinki (CONEP n. 1.006.467).

\subsection{Insomnia}

Insomnia was assessed with the following question: "Considering the last 12 months, how frequently do you have insomnia due to any concern? (A) Never; (B) Rarely; (C) Sometimes; (D) Frequently; (E) Very frequently." Adolescents who reported frequently and very frequently were classified as having insomnia.

\subsection{Physical activity and sedentary behavior}

Physical activity and sitting time were self-reported using an adaptation of the long version of the International Physical Activity Questionnaire (IPAQ). The questionnaire was modified to be specific to adolescents. The occupation domain section was changed to questions asking about physical education classes, and specific questions focusing on transportation to school. Also, questions regarding after school exercise/sports practice were included. This modified instrument has been shown to be valid and reliable in Brazilian adolescents (Tavares et al., 2014). Total physical activity was calculated as weekly minutes (min/week) of physical activity scores across the different domains (active transport, leisure physical activity and physical education classes). The participants were also asked about their total time watching television (TV) per day and total time spent sitting or in reclining position. For the analysis of the interaction between TV viewing and physical activity, we adopted the international cut points of $\geq 2 \mathrm{~h} /$ day of TV viewing and $<420 \mathrm{~min} /$ week of physical activity as risks of not complying with sedentary behavior and physical activity guidelines (American Academy of Pediatrics. Committee on Public Education, 2001; World Health Organization, 2010). Moreover, because prevalence of TV viewing is very high and that of physical activity is low and $<2 \mathrm{~h}$ /day may not sufficiently discriminate risks in Brazilian adolescents (Coledam et al., 2014; Guerra et al., 2016), we adopted an 
alternative cut point of $\geq 4 \mathrm{~h} /$ day of TV viewing and $<300 \mathrm{~min} /$ week of physical activity as risk of not complying with sedentary behavior and physical activity guidelines.

\subsection{Covariates}

Chronological age and race were self-reported by participants; race was classified as white and non-white in our study. Information on country regions (north, northeast, southeast, south and midwest) and type of city (capital or interior) was also collected as covariate. Goodies consumption was assessed through the question: "Considering the last week, how many days did you eat goodies? (sweets, candies, chocolate and others)". Response options were categorized as: 0 times, 1-3 times and more than 4 times. Ultra-processed food consumption was assessed through the question: "Considering the last week, how many days did you eat industrialized/ultra-processed food as hamburger, ham, mortadella, salami, sausage, sausage, instant noodles, packet salt, crackers, salty and others?", and response categorized into the following groups: 0 times, 1-3 times and more than 4 times.

\subsection{Statistical analysis}

For descriptive analyses, the values of frequencies as well as $95 \%$ confidence intervals $(95 \% \mathrm{CI})$ were computed. Chi-square tests were used for difference between sexes. Logistic regression analyses, with odds ratio (CI95\%) adjusted for chronological age, race, type of city (capital or interior), country regions, physical activity/sitting time, goodies ingestion and ultra-processed foods ingestion were conducted for the main analysis of association between physical activity, sitting time, TV viewing and insomnia among adolescents. All analyses were conducted using sampling weights (svy command) in STATA 15.0, adopting $p<0.05$.

\section{Results}

In total, 100,839 adolescents were included in the final sample and 100,595 for analyses including dietary patterns. The mean age of the sample was 14.28 years (range: $11-18$ years) and about $51 \%$ of them were girls. Characteristics of sample are described in Table 1. Prevalence of insomnia due to concerns was greater among girls when compared to boys [boys: $6.9 \% \quad(6.5-7.3 \%)$ vs. girls: $15.5 \%$ (14.9-16.0\%); $p<0.001]$. Higher physical activity levels and lower sitting time and TV viewing were observed among boys than in girls $(p<0.001)$.

Prevalence of insomnia according to sitting time and TV viewing patterns is described in Fig. 1. Adolescents who spent more time sitting and TV viewing were at higher risk for insomnia due to concerns, also confirmed through the logistic regressions of Table 2, given that adolescents who spent more than $8 \mathrm{~h}$ /day in sitting positions were $139 \%$ (boys) and $117 \%$ (girls) more likely to present insomnia due to concerns. Also, boys and girls who watch TV more than $8 \mathrm{~h} /$ day had respectively $149 \%$ and $72 \%$ more chance to present insomnia due to concerns, when compared to adolescents who reported between $2.01 \mathrm{~h} /$ day and $3 \mathrm{~h}$ /day of sitting time/TV viewing (group of lower insomnia's prevalence). Adolescents who watched less than one hour of TV per day also presented a greater prevalence of insomnia [boys: $7.8 \%$ (7.1-8.7\%); girls: $17.1 \%$ (15.9-18.3\%)], as well as a higher likelihood of insomnia independent from other confounders [boys: $\mathrm{OR}=1.66$ (95\%CI $=1.33-2.08)$. Girls: $\mathrm{OR}=1.42(95 \% \mathrm{CI}=1.22$ to 1.66$)$.

Fig. 2 presents the prevalence of insomnia according to physical activity patterns. Higher physical activity levels were only associated with a lower prevalence of insomnia in boys. An amount of at least 60 min of physical activity per week was increasingly associated with less insomnia until 179 min per week. Between $180 \mathrm{~min}$ and 419 min per week the lower risk remains the same for boys and girls, while more than 420 min of physical activity per week increases the risk among girls $(p<0.001)$, but with no significant difference from the group of $0 \mathrm{~min} /$ week of physical activity in the adjusted analyses $(p>0.05)$.

The co-occurrence of physical activity participation and sitting time in predicting insomnia is presented in Fig. 3. More than $4 \mathrm{~h}$ of sitting time per day was associated with higher risk for insomnia in boys and girls who comply [boys: $\mathrm{OR}=1.43(95 \% \mathrm{CI}=1.19-1.73)$; girls: $\quad \mathrm{OR}=1.66(95 \% \mathrm{CI}=1.41-1.94)]$ and who do not comply with the $300 \mathrm{~min} /$ week of physical activity recommendation [boys $=\mathrm{OR}=1.35(95 \% \mathrm{CI}=1.13-1.60) ;$ girls: $\mathrm{OR}=1.38(95 \% \mathrm{CI}=$ 1.20-1.57)].

\section{Discussion}

Our study aimed to evaluate the association between physical activity, TV viewing, total sitting time and insomnia in a representative sample of Brazilian adolescents. We show that more time spent sitting and viewing TV and less time spent physically active were associated with more insomnia. More than $4 \mathrm{~h}$ of sitting time per day was associated with the highest risk irrespective of physical activity levels. There were some differences between boys and girls. Especially among girls, the highest levels of physical activity (more than 420 min per week) were associated with a higher risk for insomnia.

The most consistent finding was that more time spent watching TV is associated with more insomnia. This way, our study from a middleincome country supports previous findings from high-income countries (Hale and Guan, 2015) showing that television watching is associated with significantly delayed bedtime or shortened total sleep time in adolescents.

Of interest and different with findings from high income countries was that less than $1 \mathrm{~h}$ of TV viewing was also associated with a higher risk for insomnia. One hypothesis is that no or very limited time spent viewing TV might be a measure-of-proxy for a lower socioeconomic status (not having a TV at home), which is a known risk factor for insomnia in adolescents (von Soest et al., 2012). Physical activity was associated with less insomnia among boys. While in girls, moderate levels of physical activity were associated with less insomnia but high levels (above $420 \mathrm{~min}$ per week) were related to more insomnia. These results corroborate previous findings of European adolescents (McMahon et al., 2017), which found a dose-response association between physical activity and negative mental health outcomes among boys and a curvilinear association among girls. It might be that a subgroup of girls reporting very high levels of daily physical activity include adolescents who over-exercise and suffer from eating disorders or other psychopathology (Smith et al., 2013), which is associated with insomnia.

There are likely psycho-social and biological mechanisms underlying the protective effect of physical activity on insomnia risk in boys and girls who do not over-exercise. Physical activity may improve mental health by enhancing monoamine levels through increased neurotransmitter activity and increased levels of endorphins or moderate activation of the limbic system and reduce levels of cortisol secretion (Alghadir et al., 2016; Rethorst et al., 2011). Improved mental health is associated with less insomnia. Other proposed mechanisms include body temperature changes, cytokine concentration changes, changes in heart rate and heart rate variability, growth hormone secretion, brain derived neurotropic factor secretion, improved fitness levels and body composition changes (Kredlow et al., 2015).

Our data cannot provide a causal inference about the associations between higher sedentary levels and more insomnia. However, some previous studies can provide some indications of a potentially causal relationship, which will underpin our assertions. For instance, previous research from randomized controlled trials in Western samples has demonstrated the independent deleterious impact of increasing sedentary behavior on mood and in particular symptoms of anxiety in active youth (Edwards and Loprinzi, 2016), possibly through changes in inflammation (Endrighi et al., 2016). Previous research has also 
suggested that sedentary behavior is associated with inflammation, most notably c-reactive protein and interleukin 6 (Henson et al., 2013). There is some provisional evidence in adults to suggest that standing and breaking up prolonged periods of sedentary behavior can improve inflammatory biomarkers profiles (Healy et al., 2011), while in adolescents metabolic benefits were observed (Fletcher et al., 2017). In addition, children and adolescents may be more vulnerable to physiological responses from arousal of the central nervous system and associated negative effects on sleep patterns with high rates of TV viewing (Hamer et al., 2009, 2011).

The findings of the present study should however be considered with caution. First of all, the design of this study was cross-sectional, and causality cannot be inferred. Adolescents with higher reported levels of insomnia may choose to be less physically active because they are experiencing fatigue and volition during waking hours and consequently prefer to be more involved in socially isolated activities such as TV viewing and other sedentary activities. The other way around being less physically active and watching more TV may act to increase insomnia risk. More comprehensive longitudinal studies are needed to better understand the complex and potentially reciprocal relationship between these variables. Second, potential confounders such as the socio-economic status and symptoms of depression and anxiety were not controlled for in the analyses. On the other hand, we presented data on combined physical activity and sedentary behaviors from a large national representative sample of adolescents from a developing country, providing new insight from an understudied population.

Future interventions based on the current findings may consider investigating the potential benefits of replacing cognitive passive solitary sedentary behaviors such as watching TV with cognitive more active sedentary behaviors such as reading or spending time with friends. Types of intervention to reduce total sitting time that should be explored in a low income setting is sitting-standing workplaces in classrooms, which have been shown to decrease sedentary behavior without impact on learning in Western settings (Clemes et al., 2016; Erwin et al., 2017).

In conclusion, a higher sitting time and a lower physical activity were associated with a greater prevalence of insomnia among adolescents in Brazil. Similarly, a higher TV viewing was also associated with a greater prevalence of insomnia, but a lower TV viewing $(<1 \mathrm{~h})$ was related to a greater prevalence of insomnia and 3-4h seems to be a threshold for an increased insomnia risk. Moreover, more than $4 \mathrm{~h}$ of sitting time per day was associated with the highest risk irrespective of physical activity levels. Finally, more than $420 \mathrm{~min} /$ week of physical activity was related to insomnia only among girls. Although further evidence is needed, interventions focusing on reducing time spent in TV viewing and sitting may be relevant for controlling and preventing sleep difficulties among Brazilian adolescents.

\section{Funding}

This research received no specific grant from any funding agency in the public, commercial, or not-for-profit sectors.

\section{Conflict of interest}

The authors declare that they have no conflicts of interest.

\section{Ethics approval}

All procedures performed in the original studies involving human participants were approved by national council of ethics in research (CONEP: 10853812.7.0000.0008) in accordance with the ethical standards of the institutional and/or national research committee and with the 1964 Helsinki Declaration and its later amendments or comparable ethical standards.

\section{Informed consent}

Informed consent was obtained from all individual participants included in the study.

\section{References}

Alghadir, A.H., Gabr, S.A., Al-Eisa, E., 2016. Effects of physical activity on trace elements and depression related biomarkers in children and adolescents. Biol. Trace Elem. Res. 172, 299-306. https://doi.org/10.1007/s12011-015-0601-3.

American Academy of Pediatrics. Committee on Public Education, 2001. American academy of pediatrics: children, adolescents, and television. Pediatrics 107, 423-426. https://doi.org/10.1542/peds.2005-1877.

American Psychiatric Association, 2013. Diagnostic and statistical manual of mental disorders (DSM-5). Washington, DC.

Arat, G., Wong, P.W.-C., 2017. The relationship between physical activity and mental health among adolescents in six middle-income countries: a cross-sectional study. Child Youth Serv. 38, 180-195. https://doi.org/10.1080/0145935X.2017.1297202.

Bootzin, R.R., Stevens, S.J., 2005. Adolescents, substance abuse, and the treatment of insomnia and daytime sleepiness. Clin. Psychol. Rev. 25, 629-644. https://doi.org/ 10.1016/j.cpr.2005.04.007.

Brunetti, V.C., O'Loughlin, E.K., O'Loughlin, J., Constantin, E., Pigeon, É., 2016. Screen and nonscreen sedentary behavior and sleep in adolescents. Sleep Heal. 2, 335-340. https://doi.org/10.1016/j.sleh.2016.09.004.

Clemes, S.A., Barber, S.E., Bingham, D.D., Ridgers, N.D., Fletcher, E., Pearson, N., Salmon, J., Dunstan, D.W., 2016. Reducing children's classroom sitting time using sit-to-stand desks: findings from pilot studies in UK and Australian primary schools. J. Public Heal. (United Kingdom) 38, 526-533. https://doi.org/10.1093/pubmed/fdv084.

Coledam, D.H.C., Ferraiol, P.F., Pires Jr., R., Ribeiro, E.A.G., Ferreira, M.A.C., de Oliveira, A.R., Pires, R., Ribeiro, E.A.G., Ferreira, M.A.C., de Oliveira, A.R., 2014. Agreement between two cutoff points for physical activity and associated factors in young individuals. Rev. Paul. Pediatr. 32, 215-222. https://doi.org/10.1590/01030582201432311.

Countryman, A.J., Saab, P.G., Llabre, M.M., 2013. Cardiometabolic risk in adolescents: associations with physical activity, fitness, and sleep-in response to Kawada. Ann. Behav. Med. 46, 403-404. https://doi.org/10.1007/s12160-013-9541-3.

de Zambotti, M., Goldstone, A., Colrain, I.M., Baker, F.C., 2017. Insomnia disorder in adolescence: diagnosis, impact, and treatment. Sleep Med. Rev E-pub ahead of print. https://doi.org/10.1016/j.smrv.2017.06.009.

Edwards, M.K., Loprinzi, P.D., 2016. Experimentally increasing sedentary behavior results in increased anxiety in an active young adult population. J. Affect. Disord. 204, 166-173. https://doi.org/10.1016/j.jad.2016.06.045.

Endrighi, R., Steptoe, A., Hamer, M., 2016. The effect of experimentally induced sedentariness on mood and psychobiological responses to mental stress. Br. J. Psychiatry 208, 245-251. https://doi.org/10.1192/bjp.bp.114.150755.

Erwin, H., Beighle, A., Routen, A., Montemayor, B., 2017. Perceptions of using sit-tostand desks in a middle school classroom. Health Promot. Pract. 1, 152483991773004. https://doi.org/10.1177/1524839917730046.

Fletcher, E.A., Salmon, J., McNaughton, S.A., Orellana, L., Wadley, G.D., Bruce, C., Dempsey, P.C., Lacy, K.E., Dunstan, D.W., 2017. Effects of breaking up sitting on adolescents' postprandial glucose after consuming meals varying in energy: a crossover randomised trial. J. Sci. Med. Sport E-pub ahead of print. https://doi.org/10. 1016/j.jsams.2017.06.002.

Guerra, P.H., Júnior, Farias, de, J.C., Florindo, A.A., 2016. Sedentary behavior in Brazilian children and adolescents: a systematic review. Rev. Saude Publica 50, 1-15. https://doi.org/10.1590/S1518-8787.2016050006307.

Hale, L., Guan, S., 2015. Screen time and sleep among school-aged children and adolescents: a systematic literature review. Sleep Med. Rev. 21, 50-58. https://doi.org/ 10.1016/j.smrv.2014.07.007.

Hamer, M., Stamatakis, E., 2014. Prospective study of sedentary behavior, risk of depression, and cognitive impairment. Med. Sci. Sports Exerc. 46, 718-723. https://doi. org/10.1249/MSS.0000000000000156.

Hamer, M., Stamatakis, E., Mishra, G., 2009. Psychological distress, television viewing, and physical activity in children aged 4 to 12 years. Pediatrics $123,1263-1268$. https://doi.org/10.1542/peds.2008-1523.

Healy, G.N., Matthews, C.E., Dunstan, D.W., Winkler, E.A.H., Owen, N., 2011. Sedentary time and cardio-metabolic biomarkers in US adults: NHANES 2003-06. Eur. Heart J. 32, 590-597. https://doi.org/10.1093/eurheartj/ehq451.

Henson, J., Yates, T., Biddle, S.J.H., Edwardson, C.L., Khunti, K., Wilmot, E.G., Gray, L.J., Gorely, T., Nimmo, M.A., Davies, M.J., 2013. Associations of objectively measured sedentary behaviour and physical activity with markers of cardiometabolic health. Diabetologia 56, 1012-1020. https://doi.org/10.1007/s00125-013-2845-9.

Hume, C., Timperio, A., Veitch, J., Salmon, J., Crawford, D., Ball, K., 2011. Physical activity, sedentary behavior, and depressive symptoms among adolescents. J. Phys. Act. Health 8, 152-156.

IBGE, Pesquisa Nacional de Saúde Do Escolar-PeNSE. Acessed in January 25, 2017, from: https://biblioteca.ibge.gov.br/visualizacao/livros/liv97870.pdf 2016.

Johnson, E.O., Roth, T., Schultz, L., Breslau, N., 2006. Epidemiology of DSM-IV insomnia in adolescence: lifetime prevalence, chronicity, and an emergent gender difference. Pediatrics 117, e247-e256. https://doi.org/10.1542/peds.2004-2629.

Kalak, N., Gerber, M., Kirov, R., Mikoteit, T., Yordanova, J., Pühse, U., HolsboerTrachsler, E., Brand, S., 2012. Daily morning running for 3 weeks improved sleep and psychological functioning in healthy adolescents compared with controls. J. Adolesc. Health 51, 615-622. https://doi.org/10.1016/j.jadohealth.2012.02.020. 
Koivusilta, L., Kuoppamäki, H., Rimpelä, A., 2016. Energy drink consumption, health complaints and late bedtime among young adolescents. Int. J. Public Health 61 , 299-306. https://doi.org/10.1007/s00038-016-0797-9.

Koyanagi, A., DeVylder, J.E., Stubbs, B., Carvalho, A.F., Veronese, N., Haro, J.M., Santini, Z.I., 2018. Depression, sleep problems, and perceived stress among informal caregivers in 58 low-, middle-, and high-income countries: a cross-sectional analysis of community-based surveys. J. Psychiatr. Res. 96, 115-123. https://doi.org/10.1016/j jpsychires.2017.10.001.

Kredlow, M.A., Capozzoli, M.C., Hearon, B.A., Calkins, A.W., Otto, M.W., 2015. The effects of physical activity on sleep: a meta-analytic review. J. Behav. Med. 38, 427-449. https://doi.org/10.1007/s10865-015-9617-6.

Lang, C., Kalak, N., Brand, S., Holsboer-Trachsler, E., Pühse, U., Gerber, M., 2016. The relationship between physical activity and sleep from mid adolescence to early adulthood. A systematic review of methodological approaches and meta-analysis. Sleep Med. Rev. 28, 32-45. https://doi.org/10.1016/j.smrv.2015.07.004.

Lange, K., Cohrs, S., Skarupke, C., Görke, M., Szagun, B., Schlack, R., 2017. Electronic media use and insomnia complaints in German adolescents: gender differences in use patterns and sleep problems. J. Neural Transm. 124, 79-87. https://doi.org/10. 1007/s00702-015-1482-5.

McMahon, E.M., Corcoran, P., O'Regan, G., Keeley, H., Cannon, M., Carli, V., Wasserman, C., Hadlaczky, G., Sarchiapone, M., Apter, A., Balazs, J., Balint, M., Bobes, J., Brunner, R., Cozman, D., Haring, C., Iosue, M., Kaess, M., Kahn, J.P., Nemes, B., Podlogar, T., Poštuvan, V., Sáiz, P., Sisask, M., Tubiana, A., Värnik, P., Hoven, C.W., Wasserman, D., 2017. Physical activity in European adolescents and associations with anxiety, depression and well-being. Eur. Child Adolesc. Psychiatry 26, 111-122. https://doi.org/10.1007/s00787-016-0875-9.

Mozafarian, N., Motlagh, M.E., Heshmat, R., Karimi, S., Mansourian, M., Mohebpour, F., Qorbani, M., Kelishadi, R., 2017. Factors associated with screen time in Iranian children and adolescents: the CASPIAN-IV study. Int. J. Prev. Med. 8, 31. https://doi. org/10.4103/ijpvm.IJPVM 3617.

Owens, J., 2014. Insufficient sleep in adolescents and young adults: an update on causes and consequences. Pediatrics 134, e921-e932. https://doi.org/10.1542/peds.20141696.

Owens, J.A., Babcock, D., Blumer, J., Chervin, R., Ferber, R., Goetting, M., Glaze, D., Ivanenko, A., Mindell, J., Rappley, M., Rosen, C., Sheldon, S., 2005. The use of pharmacotherapy in the treatment of pediatric insomnia in primary care: rational approaches. A consensus meeting summary. J. Clin. Sleep Med. 1, 49-59.

Owens, J.A., Mindell, J., Baylor, A., 2014. Effect of energy drink and caffeinated beverage consumption on sleep, mood, and performance in children and adolescents. Nutr.
Rev. 72 (Suppl 1), 65-71. https://doi.org/10.1111/nure.12150.

Peltzer, K., Pengpid, S., 2017. Sleep duration, sleep quality, body mass index, and waist circumference among young adults from 24 low- and middle-income and two highincome countries. Int. J. Environ. Res. Public Health 14, 566. https://doi.org/10. 3390/ijerph14060566.

Rethorst, C.D., Landers, D.M., Nagoshi, C.T., Ross, J.T.D., 2011. The association of 5 HTTLPR genotype and depressive symptoms is moderated by physical activity. J. Psychiatr. Res. 45, 185-189. https://doi.org/10.1016/j.jpsychires.2010.05.007.

Roberts, R.E., Roberts, C.R., Duong, H.T., 2008. Chronic insomnia and its negative consequences for health and functioning of adolescents: a 12-month prospective study. J. Adolesc. Health 42, 294-302. https://doi.org/10.1016/j.jadohealth.2007.09.016.

Sallis, J.F., Bull, F., Guthold, R., Heath, G.W., Inoue, S., Kelly, P., Oyeyemi, A.L., Perez, L.G., Richards, J., Hallal, P.C., Lancet Physical Activity Series 2 Executive Committee, 2016. Progress in physical activity over the Olympic quadrennium. Lancet (London, England) 388, 1325-1336. https://doi.org/10.1016/S0140-6736(16)30581-5.

Smith, A.R., Fink, E.L., Anestis, M.D., Ribeiro, J.D., Gordon, K.H., Davis, H., Keel, P.K., Bardone-Cone, A.M., Peterson, C.B., Klein, M.H., Crow, S., Mitchell, J.E., Crosby, R.D., Wonderlich, S.A., le Grange, D., Joiner, T.E., 2013. Exercise caution: over-exercise is associated with suicidality among individuals with disordered eating. Psychiatry Res. 206, 246-255. https://doi.org/10.1016/j.psychres.2012.11.004.

Stranges, S., Tigbe, W., Gómez-Olivé, F.X., Thorogood, M., Kandala, N.-B., 2012. Sleep problems: an emerging global epidemic? Findings from the INDEPTH WHO-SAGE study among more than 40,000 older adults from 8 countries across Africa and Asia. Sleep 35, 1173-1181. https://doi.org/10.5665/sleep.2012.

Tavares, L.F., Castro, I.R.R.de, Cardoso, L.O., Levy, R.B., Claro, R.M., Oliveira, A.F.de, 2014. Validade de indicadores de atividade física e comportamento sedentário da Pesquisa Nacional de Saúde do Escolar entre adolescentes do Rio de Janeiro. Brasil. Cad. Saude Publica 30, 1861-1874. https://doi.org/10.1590/0102-311X00151913.

von Soest, T., Bramness, J.G., Pedersen, W., Wichstrøm, L., 2012. The relationship between socio-economic status and antidepressant prescription: a longitudinal survey and register study of young adults. Epidemiol. Psychiatr. Sci. 21, 87-95.

Wong, M.M., Brower, K.J., Craun, E.A., 2016. Insomnia symptoms and suicidality in the National Comorbidity Survey-adolescent supplement. J. Psychiatr. Res. 81, 1-8. https://doi.org/10.1016/j.jpsychires.2016.06.004

World Health Organization, 2010. Global recommendations on physical activity for health. Geneva.

Zhou, E.S., Owens, J., 2016. Behavioral treatments for pediatric insomnia. Curr. Sleep Med. Reports 2, 127-135. https://doi.org/10.1007/s40675-016-0053-0. 